\title{
Comment
}

DO WE KNOW THE VALUE OF WHAT WE ARE DOING?

\section{Impacts of science communication on publics, cities and actors}

\section{Gema Revuelta}

\begin{abstract}
An evaluation toolkit developed as part of the EU-funded PLACES project was applied in 26 case studies across Europe. Results show, among other things, the contribution of science communication initiatives to public curiosity, professional networking and perception of cities where these initiatives are stronger.
\end{abstract}

Identifying the effects of science communication initiatives and policies (SCIPs) and the main recipients of such effects is not easy and some authors have even questioned the existence of them. [1]

As part of the European project PLACES (Platform of Local Authorities and Communicators Engaged in Science), ${ }^{1}$ a group of 28 independent researchers with experience in the field of science in society were contracted to assess the impact of SCIPs from all over Europe. Their mission was not only to gather data but also to elaborate common methodologies and recommendations for future actions in this field.

This group developed the PLACES Toolkit for the Impact Assessment of Science Communication Initiatives and Policies ${ }^{2}$ and, using it, carried out 26 case studies. Results from these studies have served as a basis for recommendations ${ }^{3}$ to the European Commission and others carrying out initiatives and policies in the field of science communication and scientific culture.

The toolkit takes a triple level/dimension $(3 \times 3)$ approach, where "level" refers to the agent that is responsible for the SCIP and "dimension" to who or what is receiving the influences of SCIP. Three "levels" were considered: a) science museums and science

\footnotetext{
${ }^{1}$ PLACES is a project funded by the European Commission, FP7 (see www.openplaces.eu/).

${ }^{2}$ Full text available from www.occ.upf.edu/img/imatges_cms/TOOLKIT MAY 2012.pdf. Interactive version from www.occ.upf.

${ }^{3}$ PLACES recommendations from impact assessment at www.occ.upf.edu/img/imatges_cms/PLACES _Recommendations_from_impact_assessment.docx.
} 
centres; b) science events; and c) cities of scientific culture. "Dimensions" were also divided into three categories: a) the public sphere (visitors and citizens); b) the political sphere (local and regional dimension); and c) actors involved in SCIP themselves.

The toolkit includes quantitative and qualitative instruments (standardised surveys, semi-structured interviews, focus groups as well as analyses of documents and institutional sources) and explores impacts mainly through the experiences and views from visitors, citizens, actors and stakeholders (as observers).

Using this shared methodology, 26 case studies were carried out during 2012, covering nine science centres, eight science events and nine cities of scientific culture in 19 European countries. In total, 2321 people aged over 16 responded to standardised surveys and 258 took part in semi-structured interviews or in focus groups.

The aggregate data from surveys of visitors to science museums and science centres (SMC) or science events (SE) show that, on average, more than a half $(58.53 \%)$ are repeat visitors (they had visited the installation at least once in the past), and almost one in four $(22.68 \%)$ are frequent repeat visitors (three visits or more in the past). This high presence of repeat visitors is also confirmed by institutional sources and qualitative instruments; these repeat visitors are a very useful population with which to explore long-term impacts of science communication initiatives and policies.

Visits to a SMC or SE tend to be a social activity, that is, an experience shared within a group (mainly families, friends and classmates). With some differences between cases, average results show that the family is the most common group to visit with $(39.33 \%)$, followed by friends $(20.58 \%)$.

Interviewed visitors give abundant evidence of how visits reinforce connections between group members and help to reduce the gap between those more interested in and/or with more scientific knowledge, and those less interested in and/or with less knowledge.

When asked about their motivation to come, most visitors give answers - in a spontaneous manner - in two groups: a) "have a good time with family", "an alternative for cultural or leisure activities", "tourism"; or b) "learn something", "obtain a better understanding of the issue X".

Enjoyment of the experience is a constant for almost all visitors and is described in different ways: from a simple "have fun" to "inspire your creativity" or "make your mind travel". The following aspects are those most appreciated by visitors: "alternative/innovative ways to talk about science", "possibility to explore or experience by one-

\footnotetext{
${ }^{4}$ What is "a city of scientific culture" is a central question for PLACES and several actions were carried out in the framework of this project to get a bottom-up definition. For the purposes of the Impact Assessment group, the following operational definition was adopted:
}

A City of Scientific Culture is considered as one in which science has a strong public presence and/or notable efforts are being made to strengthen that presence. The presence of science may be indicated through public attitudes to science and the levels of attention to science centres, popular science events and publications, media science and public engagement initiatives. The efforts being made to strengthen that presence could be recognised on the existence of local policies and programmes (funding programmes, communication programmes, etc.) explicitly directed to this goal. 
self", "personal interaction with scientists", "local issues, local scientists and companies", "real contexts (universities, research centres)", "diversity of fields, concepts and approaches", "dialogue activities" and "historical value".

The majority of visitors (76.38\%) find learning in a SCIP more interesting than doing it at school (much more interesting according to 39.7\%). Despite this answer, during semi-structured interviews teachers and organisers tend to offer not a competitive but an integral view of the educational process, considering that visits to a SMC or a SE have become part of the student's school career.

Half of those surveyed felt more confident to discuss science topics after their visit and $12 \%$ felt much more confident. Regarding the effect on their intellectual curiosity, $45.14 \%$ looked for more information about issues covered by a SCIP after their last visit.

Those participating in semi-structured interviews tend to recognise effects on confidence and curiosity with less conviction, at least at first glance. Those who do recognise them, however, give strong answers. Organisers, teachers, parents and grand-parents tend to assume that SCIPs have strong effects on the choice of scientific careers, but students and other visitors are not so strongly convinced about this.

The majority of visitors $(71.7 \%$ ) agree that an SMC or SE is an important symbol of the city (26.13\% strongly agree). Such survey results are also confirmed through the qualitative research: when "ordinary" citizens participating in focus groups were invited to think about what a "city of scientific culture" could be and which were its main symbols, SMCs and SEs were quickly and spontaneously mentioned (after universities and big science infrastructures).

A large majority of visitors (79.78\%) agree that the SMC or SE has an important role in the city's cultural life (34.76\% strongly agree), and interviews confirm such results. Almost all interviewees confirm that SMCs and SEs have also increased media attention for scientific issues, particularly in small and medium-sized cities. Despite this, it should be noticed that some case studies revealed serious weaknesses in relations between SCIPs and local media.

Surveyed visitors tend to agree (52.5\%) that an SMC or SE has an important role in the city's economic development. With some exceptions, people interviewed on a qualitative basis are less convinced about it, at least at first; the most common answer was that economic impact is not the first objective of a SMC or SE. Despite this, interviewees did identify direct and immediate local socio-economic impacts such as new infrastructures and attraction of new sources of funding and sponsorship and indirect or long-term socio-economic impacts such as jobs in transport and restaurants, and increased tourism attractiveness.

In the cases where the agent explored was the city itself as a "city of scientific culture" and, regardless of different interpretations of this concept, citizens who consider themselves to be living in such a city tend to assert that programmes and policies related to it have had (and will have) a positive and strong impact on the city's development, as well as on its international visibility. 
The effect of SCIPs most commonly observed by actors involved (scientists, teachers, journalists, politics, business representatives, civil society organisations, etc.), although not always considered the most important, is their potential to increase professional networking, which, in some cases, has translated into new projects.

What scientists appreciate most is the strong and positive effect of the public's feedback. This effect is considered "as a mirror" or "a way of having a different look on them and their activity", providing them with a better understanding of public needs and concerns. Scientists also value the acquisition of communication skills from their participation in SCIPs and the visibility of their institutions and/or their field of research.

Business representatives most appreciate, aside from networking (with scientists, politicians or other colleagues from their sector), public visibility, especially since it is associated with positive values and experiences. This is particularly true in the case of SCIPs with large attendance or media coverage.

Almost all teachers consulted confirm that SCIPs have positively influenced their work and their local educational system, providing them with teaching materials and training (or updating) opportunities. Some teachers also value the effect that participating in SCIPs has had on their competitiveness compared to other teachers or schools.

Compared with previous studies, this research has pointed out the strong "socialising" effect of SCIP, as seen in: a) their contribution to science "normalization" and b) their role in strengthening group members' ties (family, friends). The known cognitive impact of SCIPs in adults and kids has been also confirmed, although it shows that there is nowadays no point in dividing informal education provided by SCIPs from formal education programmes. Effects on intellectual curiosity, increased self-esteem when talking about science topics and scientific vocations enhancement have been also confirmed, but not so categorically and with bigger differences among methodological approaches.

Finally, one of this research's main contributions has been the study of SCIPs' impact in the local or city scale. In this sense, all actors considered (citizens, communicators, business people, politicians, scientists, teachers, journalists, etc) state that local policies promoting science culture have had and/or are going to have an important role in the city regarding its economic development and visibility. Science centres and museums and science events are perceived by citizens as important symbols of their cities, especially in the context of "city of scientific culture".

\section{References}

[1] P. Persson (2000), “Community Impact of Science Centres: Is There Any?", Curator: The Museum Journal 43: 1. 


\section{Author}

Gema Revuelta is Associate Professor of Science Communication and Deputy Director of the Science Communication Observatory at the Universitat Pompeu Fabra (Barcelona, Spain). She was co-ordinator of the impact assessment project in PLACES.

E-mail: gemma.revuelta@upf.edu.

How to CITE: G. Revuelta, Impacts of science communication on publics, cities and actors, JCOM 13(01)(2014)C01. 